\title{
EDEMA PULMONAR AGUDO
}

\author{
ACUTE PULMONARY EDEMA
}

Renato Barroso Pereira de Castro

Médico Assistente. Divisão de Cardiologia. Hospital das Clinicas da Faculdade de Medicina de Ribeirão Preto - USP

CorRESPONDÊnCIA: Divisão de Cardiologia. Hospital das Clínicas da FMRP-USP.

Avenida Bandeirantes, 3.900 - CEP 14.048-900 Ribeirão Preto- SP.

CASTRO RBP. Edema pulmonar agudo. Medicina, Ribeirão Preto, 36: 200-204, abr./dez. 2003.

RESUMO - São revistos os conceitos fisiopatológicos, diagnósticos e terapêuticos do edema pulmonar agudo, com ênfase na etiologia cardiológica. O acúmulo de líquido, no espaço intersticial pulmonar, respeita a dinâmica observada em qualquer outro território e se faz, inicialmente, no espaço peribronquiolar e, posteriormente, na região perialveolar inundando, a seguir, a própria luz do alvéolo. A integridade da membrana alveolocapilar é fator fundamental e está mais ou menos comprometida, segundo a etiologia do edema. O diagnóstico é essencialmente clínico, mas a investigação adicional, por recursos diagnósticos vários, é fundamental. A terapêutica fundamenta-se no fornecimento de oxigênio em níveis suficientes, ao mesmo tempo em que se promove a normalização da função de hematose, reduzindo-se o líquido acumulado no interstício e restaurando-se a integridade da barreira alveolocapilar. O pronto reconhecimento e o início do tratamento são fundamentais na tentativa de reduzirmos o prognóstico ominoso dessa entidade clínica.

UNITERMOS - Edema Pulmonar Agudo. Insuficiência Respiratória Aguda.

\section{1- INTRODUÇÃO}

Edema pulmonar agudo constitui urgência clínica e motivo freqüente de internação hospitalar. $\mathrm{O}$ paciente apresenta-se extremamente dispnéico, cianótico e agitado, evoluindo com rápida deterioração para torpor, depressão respiratória e, eventualmente, apnéia com parada cardíaca. De diagnóstico essencialmente clínico, é fundamental, portanto, que o socorrista esteja habilitado a reconhecer e iniciar o tratamento de tão grave entidade.

\section{2- FISIOPATOLOGIA}

Os mecanismos mais freqüentes envolvem: 1) o desbalanço nas forças que regem as trocas de fluido entre intravascular e interstício ou 2) a ruptura da membrana alveolocapilar; independente do mecanis- mo iniciante, uma vez que ocorra a inundação do alvéolo, sempre está presente algum grau de ruptura da mesma. (Ver Tabela I).

A sequiência de acúmulo de líquido independe do mecanismo desencadeador, é sempre a mesma e pode ser dividida em três estágios: 1) aumento do fluxo de líquidos dos capilares para o interstício, sem que se detecte, ainda, aumento do volume intersticial pulmonar devido ao aumento paralelo, compensatório, da drenagem linfática; 2) o volume que é filtrado pelos capilares ultrapassa a capacidade de drenagem linfática máxima e inicia-se o acúmulo de líquido no interstício; inicialmente, este ocorre de modo preferencial junto aos bronquíolos terminais, onde a tensão intersticial é menor; 3) aumentos adicionais do volume, no interstício, terminam por distender os septos interalveolares e conseqüente inundação dos alvéolos. 
Tabela I - Classificação do Edema Pulmonar segundo sua Fisiopatologia

\section{I- Desbalanço das forças de Starling}

A- Aumento da pressão capilar pulmonar

1) aumento da pressão venosa pulmonar, sem falência do V.E. (estenose mitral)

2) aumento da pressão venosa pulmonar, com falência do V.E.

B- Redução da pressão oncótica plasmática: hipoalbuminemia, por ex.

C- Aumento da negatividade da pressão intersticial 1) rápida correção de pneumotórax

2) obstrução respiratória aguda (asma)

II- Alteração da permeabilidade alveolocapilar (síndrome da angústia respiratória aguda)

A- Pneumonia (bacteriana, viral, etc.)

B- Inalação de substâncias tóxicas

C- Toxinas circulantes (bacterianas, venenos, etc.)

D- Aspiração do conteúdo gástrico

E- Pneumonite aguda por radiação

F. Coagulação Intravascular Disseminada

G- Imunológico (reações de hiperssensibilidade)

H- Trauma não torácico

I- Pancreatite Hemorrágica Aguda

\section{III- Insuficiência Linfática}

A- Após transplante pulmonar

B- Carcinomatose linfangítica

C- Linfangite fibrosante (ex.: silicose pulmonar)

\section{IV-Etiologia desconhecida}

A- Edema pulmonar das grandes altitudes

B- Edema pulmonar neurogênico

C- Embolia pulmonar

D- Pós-anestesia e pós-cardioversão

O edema pulmonar se instala, quando o fluxo de líquido do espaço intravascular, em direção ao interstício e alvéolos, supera o retorno do mesmo ao intravascular e sua drenagem pelos linfáticos. Estes desempenham importante papel na remoção de líquidos do interstício pulmonar: estima-se que um adulto de $70 \mathrm{Kg}$ tenha um fluxo linfático pulmonar de $20 \mathrm{ml} / \mathrm{h}$ e que este possa sofrer incrementos adaptativos, atingindo até $200 \mathrm{ml} / \mathrm{h}$. Para que isso seja observado, entretanto, é necessário que o aumento na pressão capilar pulmonar ocorra de modo gradual. Elevações abruptas da mesma podem ser fatais num paciente não pré-condicionado para hipertrofia do sistema linfático pulmonar. Causas freqüentes de edema pulmonar cardiogênico são: infarto miocárdico agudo ou exacerbação isquêmica de disfunção ventricular pré-existente, sobrecargas agudas de volume para o ventrículo esquerdo (insuficiências valvares, rotura do septo interventricular) e a estenose mitral.

Existem situações, entretanto, em que o acúmulo de líquido e proteínas, na luz alveolar, não se deve, primariamente, à elevação da pressão na luz dos capilares pulmonares. O termo Síndrome da Angústia Respiratória do Adulto (SARA) refere-se a vários processos pulmonares difusos, agudos ou sub-agudos, que resultam em hipoxemia severa. Representa a forma mais grave de edema pulmonar, devido a lesão da membrana alveolocapilar. Dentre suas causas, podemos salientar aquelas de natureza local e as sistêmicas. As agressões primárias ou diretas à membrana alveolocapilar, geralmente, resultam da exposição a agentes químicos, infecciosos, líquido gástrico ou gases tóxicos, sempre associados a destruição celular maciça. Danos secundários associam-se, em geral, à ativação de cascatas bioquímicas sistêmicas, com geração de agentes oxidantes, mediadores inflamatórios e enzimas, com semelhante potencial destrutivo à membrana alveolocapilar, associados, por exemplo, a pancreatite, trauma grave, politransfusões, etc. Descrevem-se, em geral, três fases distintas, na instalação da SARA: 1) fase exsudativa, caracterizada por edema intersticial de alto teor protéico e rápida invasão alveolar, associada a hemorragia e subseqüente formação de membrana hialina; 2) proliferativa, caracterizada pela organização do exsudato fibrinoso e 3) fibrosante, marcada pela regeneração do epitélio alveolar e espessamento dos septos interalveolares, resultando em graus variáveis de tecido cicatricial. Radiologicamente, observamos sinais iniciais de edema intersticial, seguidos de velamento alveolar e broncogramas; em contraste com o edema de origem hidrostática, tem distribuição mais periférica e nota-se a ausência de achados típicos dele, como a cardiomegalia, redistribuição vascular e linhas B de Kerley. Com a evolução para a fase proliferativa, padrão de "vidro fosco" de distribuição não homogênea passa a se 
evidenciar; nessa fase, lesões císticas intra-parenquimatosas e subpleurais podem acarretar pneumotórax. Episódios exsudativos recorrentes podem ocorrer nas fases proliferativa e fibrosante, resultando em padrões radiológicos mistos, ocasionalmente exibindo características comuns às três fases.

Pouco sintomática, nas etapas iniciais, a SARA pode evoluir rapidamente para dispnéia progressiva, taquipnéia e cianose. A hipoxemia se instala, caracteristicamente refratária à oxigenioterapia, devido ao shunt arteriovenoso. A ventilação mecânica com pressão positiva expiratória final é freqüentemente necessária para adequada expansão do parênquima pulmonar e melhor difusão do oxigênio.

\section{3- QUADRO CLÍNICO/ DIAGNÓSTICO}

As manifestações dependem do estágio em que se encontra o paciente. Assim, na fase 1, apenas a dispnéia de esforço costuma ser correlacionada; já, na fase 2, o acúmulo inicial de líquido, no interstício pulmonar, pode comprometer as vias aéreas de pequeno diâmetro (terminais), particularmente nas bases pulmonares, associando-se a broncoespasmo reflexo. A taquipnéia passa a ser observada, bem como os sibilos expiratórios. É comum o diagnóstico indevido de doença pulmonar obstrutiva ou de asma, em pacientes com manifestações iniciais de congestão pulmonar. Radiologicamente, a fase 2 é caracterizada por borramento peri-hilar bilateral e espessamento dos septos interlobulares (linhas “B” de Kerley). Ortopnéia pode, ocasionalmente, ocorrer. Com o progredir do quadro (fase 3), o acúmulo de grandes quantidades de líquido no interstício pulmonar leva ao extravasamento para a luz alveolar, presenciando-se, então, as manifestações clínicas em toda a sua dramaticidade. O sério comprometimento da hematose leva à dispnéia intensa, com o paciente nitidamente ansioso, assumindo posição ortostática e utilizando a musculatura respiratória acessória; palidez cutânea, cianose e frialdade de extremidades, associadas a agitação e ansiedade, bem como respiração ruidosa facilitam o reconhecimento dessa urgência clínica e obviam a necessidade de terapêutica imediata. Se ela for retardada, podem surgir a obnubilação e o torpor, expressões clínicas do evento mais temido no contexto - a narcose - a qual pode prenunciar a parada respiratória e a morte. $\mathrm{O}$ edema pulmonar agudo constitui experiência aterrorizante para o paciente e para os circunstantes. As vias aéreas, repletas de secreção causam a sensação nítida de afogamento; o esforço respiratório leva à sobrecarga adicional sobre o ventrículo esquerdo, o que, associado à piora da hipóxia, pode desencadear um círculo vicioso letal. A ausculta pulmonar, na fase 3 , revela a presença de estertores grossos, roncos e sibilos, inicialmente restritos às bases pulmonares, mas, rapidamente, progressivos até os ápices pulmonares. A ausculta cardíaca, freqüentemente, é difícil, podendo revelar, entretanto, a presença de terceira bulha $\mathrm{e}$ hiperfonese do componente pulmonar da segunda bulha. A pressão arterial, freqüentemente, está elevada, dada a intensa atividade adrenérgica; sua normalização ocorre, na maioria das vezes, com as medidas terapêuticas para o edema pulmonar. Quando a hipertensão arterial constituir fator desencadeador da congestão pulmonar, terapêuticas específicas para seu controle estarão indicadas. Hipotensão e choque circulatório expressam falência grave do ventrículo esquerdo, agravando sobremaneira o prognóstico. $\mathrm{O}$ quadro radiológico típico revela velamentos pulmonares do tipo alveolar, em intensidades variáveis; a área cardíaca pode ser normal (tipicamente, nos casos de insuficiência coronariana aguda, sem disfunção ventricular prévia), ou aumentada, quando em presença de cardiopatias crônicas com dilatação de ventrículo esquerdo. A gasometria arterial revela níveis progressivos de hipóxia; nas fases iniciais, a hipocarbia é a regra, devido à hiperventilação e à maior difusibilidade do gás carbônico através da barreira alveolocapilar. Como já referido, a detecção de hipercarbia pode ser prenúncio de depressão respiratória e morte.

Em resumo, o diagnóstico do edema pulmonar agudo é essencialmente clínico. Os exames complementares devem ser utilizados racionalmente, como subsídios e para balizamento das condutas terapêuticas adotadas. Nunca é demais salientar a importância da documentação adequada, principalmente a radiológica, de tão grave intercorrência na história clínica do paciente. Paralelamente ao diagnóstico e tratamento do edema pulmonar, faz-se urgente elucidarmos a etiologia do mesmo. A correta identificação do mecanismo desencadeador aumenta as chances de sucesso na terapia.

\section{4- TERAPÊUTICA}

(Restringir-nos-emos ao tratamento do edema pulmonar cardiogênico)

Medidas Gerais - É clássica a recomendação do posicionamento do paciente; na verdade, ele 
próprio tende a assumir a posição sentada, freqüentemente com os braços apoiados na beira do leito ou sobre o encosto da cadeira e com as pernas pendentes, o que permite o uso mais eficaz da musculatura acessória, a diminuição do retorno venoso e o aumento da capacidade vital. $\mathrm{O}$ decúbito horizontal é sempre mal tolerado pelo paciente consciente. $\mathrm{O}$ uso de torniquetes em extremidades, visando à redução do retorno venoso, é muito pouco utilizado nos dias de hoje. Monitorização eletrocardiográfica, acesso venoso e oxigênio por máscara deverão ser imediatamente providenciados. O oxímetro de pulso é um recurso útil na avaliação contínua da eficácia terapêutica; sua eficiência diminui nos casos de má perfusão periférica. O paciente em edema pulmonar agudo deve ser observado em unidade apropriada, com recursos adequados ao atendimento de urgências cardiológicas e na presença constante de pessoal médico, até a estabilização do quadro.

Oxigênio - Uma máscara facial de oxigênio com fluxo de 5 a 6 1/min deverá ser a opção inicial; se necessário, máscaras sem reinalação e com reservatório permitem concentrações de 90 a $100 \%$. O uso do CPAP através de máscara especial ou no paciente já entubado é bastante útil. Profissional treinado em entubação endotraqueal deverá estar disponível, bem como todo o material necessário, notadamente se: uma $\mathrm{PaO}_{2}>60 \mathrm{mmHg}$ não for obtida, mesmo com máscaras de $100 \%$, se o paciente apresenta sinais de hipóxia cerebral (letargia ou obnubilação) ou se apresenta aumentos progressivos da $\mathrm{PCO}_{2}$ ou acidose.

Diuréticos _ A furosemida tem sido considerada peça fundamental no esquema terapêutico do edema pulmonar. Tem uma ação bifásica: venodilatação imediata, com conseqüente aumento da capacitância venosa (nos primeiros $5 \mathrm{~min}$ ), seguida de diurese, com pico de efeito 30 e $60 \mathrm{~min}$. As doses são variáveis e baseiam-se na resposta terapêutica, que deverá ser avaliada após os primeiros $20 \mathrm{~min}$. A intensidade da diurese deverá ser ditada pelo grau de retenção volêmica observada e na função renal; lembrar que, na falência ventricular esquerda aguda (isquêmica por exemplo), não se observa hipervolemia e a terapêutica deverá priorizar a vasodilatação com conseqüente redução da pós-carga do VE.

Morfina - O sulfato de morfina ( 2 a $8 \mathrm{mg}$ EV, se $\mathrm{PA}>100 \mathrm{mmHg}$ ) permanece como recurso útil no edema pulmonar agudo. Tem ação venodilatadora, além de sedação ligeira, reduzindo o esforço respiratório e a ansiedade. A preocupação de muitos profissionais com seu efeito sedativo e conseqüente risco de depressão respiratória tem justificativa; pacientes de maior risco para a grave complicação do uso da morfina são aqueles com diminuição do nível de consciência ou evidências laboratoriais de retenção de $\mathrm{CO}_{2}$.

Vasodilatadores - A a nitroglicerina endovenosa tem sido considerada a droga mais efetiva no edema pulmonar cardiogênico; a venodilatação e conseqüente redução da pré-carga do ventrículo esquerdo bem como a redução da resistência vascular sistêmica (pós-carga) são a base de sua utilização. Nao deverá ser utilizada, se a pressão arterial sistêmica for inferior a $100 \mathrm{mmHg}$. A dose inicial endovenosa recomendada é de 10 a $20 \mathrm{mcg} / \mathrm{min}$ com incrementos de $5-10 \mathrm{mcg} / \mathrm{min}$, a cada 5 a $10 \mathrm{~min}$, até que se atinja a resposta terapêutica ou hipotensão $(\mathrm{PA}<100 \mathrm{mmHg}$ ). O uso de comprimidos sublinguais poderá ser útil até que um acesso venoso tenha sido obtido.

O nitroprussiato de sódio tem ações semelhantes à nitroglicerina, com discreta superioridade na ação dilatadora arterial; está indicado nos casos com hipertensão arterial mais grave. A dose endovenosa recomendada é de 0,1 a 5,0 mcg/Kg/min. O limite pressórico mínimo, de $100 \mathrm{mmHg}$ para que se possa iniciar o uso do vasodilatador, também deverá ser respeitado.

Inotrópicos - A associação de choque circulatório e edema pulmonar agudo é uma das mais graves situações com que nos deparamos na sala de urgência. Nesses casos, se a pressão arterial sistólica estiver entre 70 e $100 \mathrm{mmHg}$, inicie dopamina na dose de 2.5 a $20 \mathrm{mgc} / \mathrm{Kg} / \mathrm{min}$; se dose superior a esta for necessária, acrescente norepinefrina e reduza a dose de dopamina para $10 \mathrm{mcg} / \mathrm{Kg} / \mathrm{min}$. A dobutamina, também na dose de 2,0 a $20 \mathrm{mcg} / \mathrm{Kg} / \mathrm{min}$, deverá ser reservada para casos de hipotensão sem sinais de choque associados. A digitalização só está indicada no controle de taquiarritmias supraventriculares como a fibrilação atrial de alta resposta ventricular; sua ação inotrópica é muito retardada e não demonstra benefícios na reversão do edema pulmonar ou na estabilização hemodinâmica.

Outros recursos terapêuticos - A amrinone (dose de ataque de $0,75 \mathrm{mg} / \mathrm{Kg}$ em 2 a 3 min e manutenção de 2 a $20 \mathrm{mcg} / \mathrm{Kg} / \mathrm{min}$ ) associa efeitos inotrópicos e vasodilatadores. A aminofilina (dose de ataque de $5 \mathrm{mg} / \mathrm{Kg}$ em 10 a $20 \mathrm{~min}$, seguida de manutenção de 0,5 a $0,7 \mathrm{mg} / \mathrm{Kg} /$ hora) é útil nos pacientes que se apresentam com componente de broncoespasmo significante ("asma cardíaca") salientando-se, entretanto, o seu potencial de agravar arritmias, notadamente, no paciente portador de insuficiência coronariana. Os trombolíticos podem ser úteis no paciente 
com infarto agudo do miocárdio e falência aguda do ventrículo esquerdo; entretanto, nessa situação, dá-se preferência à angioplastia, dada sua maior efetividade na reperfusão. $O$ balão intra-aórtico constitui recurso de suporte hemodinâmico útil no contexto, como medida transitória ("ponte") até que revascularização ou melhora espontânea possam ocorrer.

\section{5- PROgNóstico}

Apesar dos avanços diagnósticos e terapêuticos, o EAP continua a apresentar prognóstico sombrio, com a mortalidade intra-hospitalar relatada variando entre 6 e 30\%; em recente publicação, Roguin et al. ${ }^{(1)}$, observando 150 casos atendidos em um hospital geral universitário, relataram mortalidade intra-hospitalar de $12 \%$ e de $40 \%$ no primeiro ano! Segundo o mesmo autor, foram preditores de mortalidade: a presença de choque/hipotensão associados, IAM associado, necessidade de assistência ventilatória mecânica, bem como evidências ecocardiográficas de disfunção ventricular sistólica.

\section{6- CONCLUSÃO}

Representando uma das mais sérias urgências clínicas a desafiar o médico socorrista, o EAP necessita de diagnóstico e tratamento imediatos; a presença constante ao lado do paciente até a completa reversão do quadro é mandatória. Pelas sérias implicações prognósticas, todo o esforço deve ser envidado não só no controle clínico da descompensação aguda, mas, também, na identificação de possíveis causas reversíveis, tais como isquemia miocárdica, taquiarritmias, defeitos valvares agudos, etc. Na eventualidade de disfunção ventricular crônica, o correto diagnóstico do fator descompensador (interrupção da medicação, erros dietéticos, infecções sistêmicas, anemia, disfunções tireoideanas, etc.) deverá ser sempre lembrado. Nunca será excessivo salientar a necessidade de evitarmos a evolução para a disfunção ventricular através da detecção precoce e do controle clínico de seus principais causadores, tais como a hipertensão arterial sistêmica, a isquemia miocárdica e o diabetes mellitus.

CASTRO RBP. Acute pulmonary edema. Medicina, Ribeirão Preto, 36: 200-204, apr./dec. 2003.

ABSTRACT - The physiopatologic, diagnostic and therapeutic aspects of acute pulmonary edema are reviewed, with emphasis on the cardiologic etiology. The liquid accumulation in the pulmonary interstitium follow the principles observed in any other territory, beginning in the peribronquiolar space, progressing to the peri-alveolar region with the inundation of the alveolar space in the end. The integrity of the alveolo-capilar membrane is damaged in different degrees according to the pathophysiological mechanism. The diagnosis is based mainly on clinical aspects, but an additional investigation using various methods may be necessary. The treatment is directed to offer oxygen and to normalize the hematosis function, diminishing the liquid accumulated in the interstitium and reestabilishing the integrity of the alveolo-capilar membrane. The immediate diagnosis and treatment are fundamental to improve prognosis.

UNITERMS - Pulmonary Edema, Acute. Respiratory Insufficiency, Acute.

\section{REFERÊNCIAS BIBLIOGRÁFICAS}

1 - ROGUIN A; BEHAR D; BEN AMI H; REISNER SA; EDELSTEIN S; LINN S \& EDOUTE Y. Long-term prognosis of acute pulmonary oedema-an ominous outcome. Eur J Heart Fail 2: 137-144, 2000.

\section{BIBLIOGRAFIA RECOMENDADA}

1 - GIVERTZ MM; COLUCCI WS \& BRAUNWALD E. Clinical aspects of heart failure: High output heart failure; pulmonary edema. In: BRAUNWALD E; ZIPES D \& LIBBY P, eds. Heart disease: A textbook of cardiovascular disease, $6^{\text {th }} \mathrm{ed}$, Saunders, Philadelphia, chapter 17, p. 534-561, 2001.

2- GUIMARÃES JI; MESQUITA ET; BOCCHI EA. Revisão das II Diretrizes da Sociedade Brasileira de Cardiologia para o diagnóstico e tratamento da insuficiência cardíaca. Arq Bras Cardiol 79: 1-30, 2002. Supl. 4.

3 - BURGHUBER OC. Respiratory effects of systemic disease. In: GIBSON GJ; ed. Respiratory medicine; 3a ed, p.19651974, Saunders, Philadelphia, 2003. 